\title{
Mondor's Disease in the Arm after Intravenous Chemotherapy Following Breast Cancer Surgery
}

\author{
Tomomi Hasegawa, MD and Yutaka Okita, MD
}

\begin{abstract}
We present a case of superficial thrombophlebitis of the arm, known as a variant of Mondor's disease. A 71-year-old woman who underwent a left simple mastectomy with axillary dissection for breast cancer had a cord-like vein structure in the right antecubital fossa following postoperative intravenous chemotherapy, and complained of limited elbow extension due to the firm and inflexible structure. She successfully underwent surgical resection of the vein cord to relieve the elbow motion limitation.
\end{abstract}

Key words: Mondor's disease, postchemotherapy, surgical resection

\section{INTRODUCTION}

$\mathrm{M}$ ondor's disease is a peculiar form of superficial thrombophlebitis that affects the subcutaneous vein, mainly of the anterolateral thoraco-abdominal wall ${ }^{1,2)}$ or rarely of other parts including axilla ${ }^{3)}$ and cervical region. ${ }^{4)}$ It usually occurs as a sudden, subcutaneous pain, and palpable and visible subcutaneous cord-like indurations. We present here a case of Mondor's disease in the right arm following breast cancer surgery and subsequent intravenous chemotherapy.

\section{Case Report}

A 71-year-old woman was referred to our department for an evaluation of a subcutaneous induration with limited elbow movement of her right arm. She underwent a simple mastectomy of the left breast with axillary dissection for stage III breast cancer one year ago, and a subsequent primary systemic chemotherapy with 4 courses of

Division of Cardiovascular Surgery, Department of Surgery, Kobe University Graduate School of Medicine, Kobe, Japan

Received: August 23, 2010 Accepted: October 29, 2010

Corresponding author: Tomomi Hasegawa, MD. Division of Cardiovascular Surgery, Department of Surgery, Kobe University Graduate School of Medicine, 7-5-2 Kusunoki-cho, Chuoku, Kobe 650-0017, Japan

Tel: +81-78-392-5942, Fax: +81-78-382-5959

E-mail: thase428@med.kobe-u.ac.jp
FEC (5-fluorouracil, epirubicin and cyclophosphamide) and 4 courses of weekly paclitaxel. Two weeks after surgery, the patient presented with a nonpainful, palpable cord-like induration in the left axilla. No extension to the left arm was observed. During an intravenous systemic chemotherapy session the patient presented with a tender, palpable cord-like induration in the right antecubital fossa with mild inflammation. She was treated with broad-spectrum oral antibiotics and anti-inflammatory agents, resulting in the relief of inflammatory symptoms. However, the cord-like induration in the right antecubital fossa became firm, and movement of the elbow joint became limited (Fig. 1). On physical examination, a 15 $\mathrm{cm}$ long, subcutaneous cord-like structure of the right radial cutaneous vein was detected, and the extension of the right elbow was limited to 145 degrees of the flexionextension arc. Three-dimensional multidetector-row computed tomography (3D-MDCT) also detected the cordlike structure with the limited elbow extension on the right arm (Fig. 2A), and ultrasonography showed a hypoechoic tubular structure without any Doppler signal (Fig. 2B). Laboratory tests, including complete blood cell count, blood sedimentation, blood clotting levels, C-reactive protein and rheumatoid factor, were performed and yielded normal results. The patient was diagnosed as having Mondor's disease on the basis of these clinical findings. Although her symptoms were followed up for more than 6 months, she continued to complain of limited movement of her right elbow with daily troubles, such as difficulty in changing clothing or cooking. Since the 


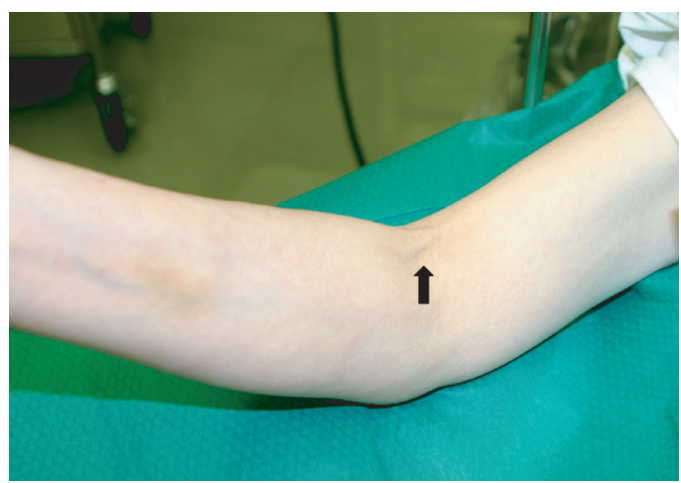

Fig. 1 Photograph of the cord-like vein structure (arrow) across the right antecubital fossa. Note the limitation in elbow extension.

elbow contracture might have developed during the longterm conservative therapy, we decided to perform a surgical resection of the cord-like vein. Under local infiltration anesthesia of $1 \%$ lidocaine, the cord-like vein was resected $4 \mathrm{~cm}$ in length through a small skin incision $(5 \mathrm{~mm})$, which followed along the natural Langer skin lines in the antecubital fossa. Immediately after surgery, the elbow was stiff with a 160 degree maximum arc of the flexionextension; however, after one week of postoperative rehabilitation, the right elbow could be fully extended. The resected vein, microscopically, was almost obliterated by a markedly concentric fibrous thickness. The vein wall had less connective tissue proliferation and lymphocyte infiltration or thrombus formation (Fig. 3A and B).

\section{Comments}

The present report described a case of Mondor's disease that had developed in the right arm, after intravenous chemotherapy, resulting in a limitation of the elbow extension. The disease also involved the left axilla, which was related to the ipsilateral mastectomy with axillar dissection for breast cancer. We surgically treated symptomatic Mondor's disease only in the right extremity and not in the left axilla.

Mondor's disease was first described by the French surgeon Henry Mondor in 1939. ${ }^{5)}$ Classical Mondor's disease affects veins in the thoraco-abdominal area, most commonly including the thoracoepigastric, lateral thoracic, and superior epigastric veins. Although Mondor's disease is considered to be a rare disorder, incidence had been increasing because of increased awareness of the disease. It occurs three times more frequently in women
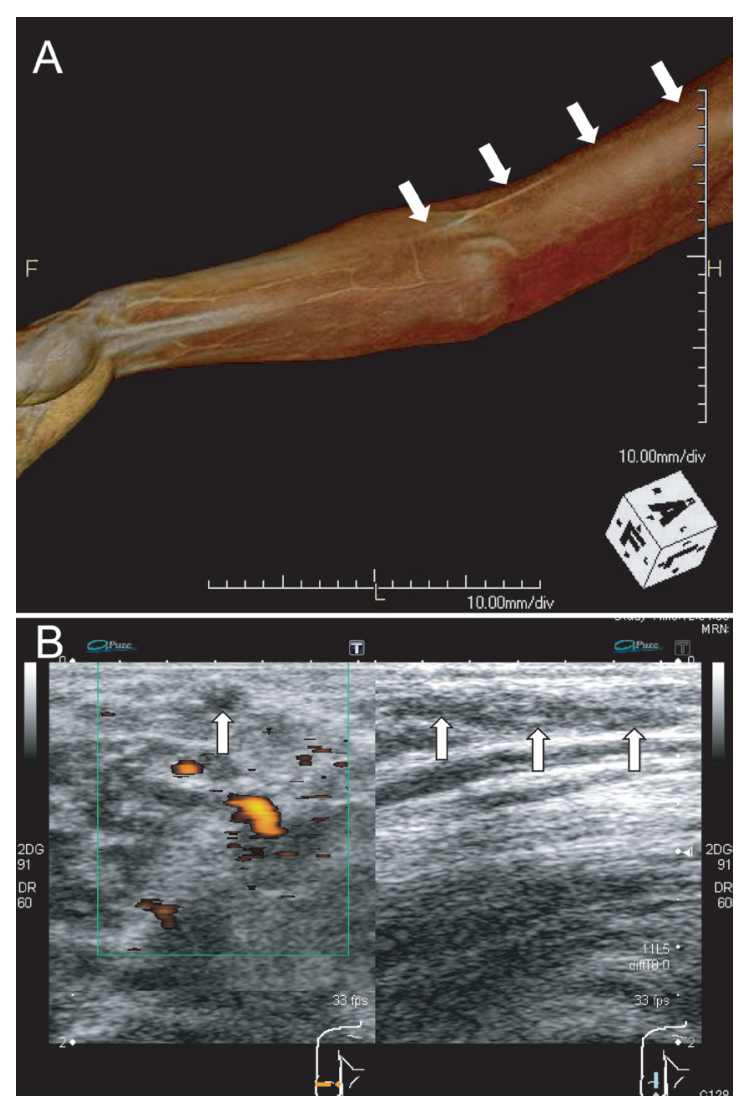

Fig. 2 Images of the cord-like vein structure.

A: Three dimensional multidetector computed tomography. Note the cord-like structure (arrows) measuring $15 \mathrm{~cm}$ in length at right upper extremity. B: Ultrasonographic images. Note the hypoechoic tubular structure (arrows) without any Doppler signal.

than in men, usually between the second and fifth decades of life. ${ }^{6}$

The etiology still remains unclear, but it has been associated more often with inflammation, infection, trauma, cancer or surgical procedure in the breast. Several predisposing factors have been described, including endothelial damage, stasis and hypercoagulable state in veins. Mondor's disease has been rarely associated with rheumatoid arthritis, febrile episodes, an immunodeficient state, pregnancy, intravenous catheters, oral contraceptives, vasoconstrictor drug use, intravenous drug use, or venous compression from tight clothing. ${ }^{7-9)}$ Generally, the etiology of Mondor's disease is considered multifactorial, and a diagnosis of Mondor's disease can be generally made only on the basis of clinical history and findings. Therefore, chemotherapy could be one of possible causative factors of Mondor's disease. 


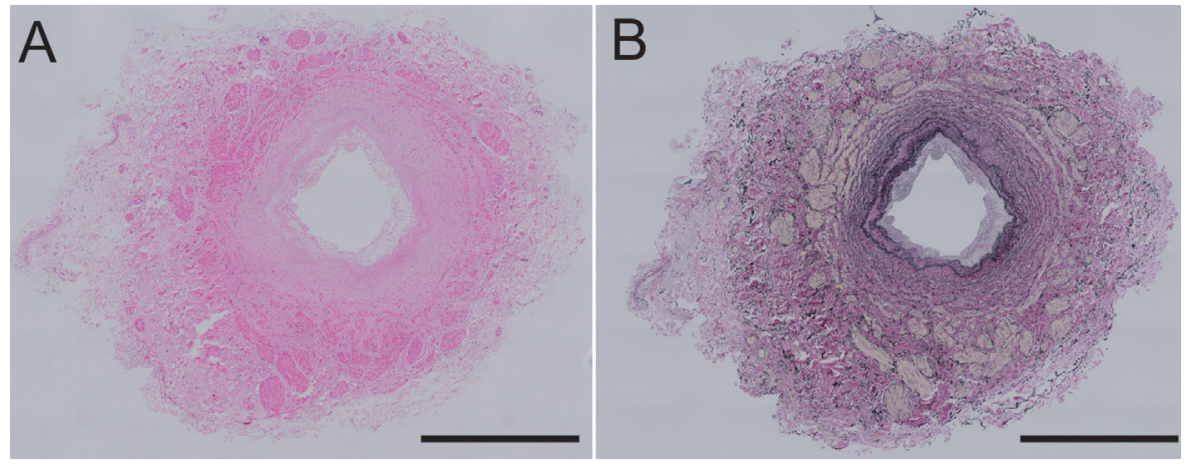

Fig. 3 Microscopic findings of the cord-like vein structure.

A: Hematoxylin and eosin stain.

B: Elastica-van Gieson's stain. Note the markedly fibrous thickness with connective tissue proliferation. Neither thrombus formation nor poor inflammatory cell infiltration was observed. Bar $=500 \mu \mathrm{m}$.

The predominant histopathologic findings of Mondor's disease were associated with obstructed or obliterated vasculitis, which develops through different stages: (1), dense inflammatory cell infiltration and thrombus formation, (2) an intimal thickening with connective tissue proliferation, resulting in the formation of a hard cord and (3) recanalization of the vein. ${ }^{10)}$ In the present case, the right radial cutaneous vein was almost obliterated by markedly fibrous thickness with connective tissue proliferation. A poor inflammatory reaction without thrombus obstruction was observed. These findings suggest that the vein was in the chronic phase of Mondor's disease.

The diagnosis of Mondor's disease is made primarily on the base of clinical history and physical examination. The use of ultrasonography, particularly color Doppler imaging, is helpful in the diagnosis and monitoring. ${ }^{7}$ In the present case, 3D-MDCT was also useful in imaging the cord-like vein structure and in the planning of the surgical procedure.

Mondor's disease is considered to be benign and selflimiting. It nearly always resolves without any treatment. Treatment should be required only if the symptoms are persistent or exacerbated. Anti-inflammatory drugs may be effective to decrease the time to resolution. When treatment is not effective or there is recurrence of disease, surgical resection of the superficial vein should be necessary. ${ }^{7)}$ In the present case, the patient complained of limited movement of her right elbow. Since elbow contracture might have been caused by the long-term conservative therapy, we decided to treat the patient surgically.

In summary, it is important to keep in mind that Mondor's disease can present as an isolated superficial thrombophlebitis on the arm after intravenous chemotherapy.
Surgical treatment can be effective for relief of limited joint movement to improve the patient's quality of life.

\section{REFERENCES}

1) Pugh CM, DeWitty RL. Mondor's disease. J Natl Med Assoc. 1996; 88: 359-63.

2) Soler-Gonzalez J, Ruiz MC. Images in clinical medicine. Mondor's disease. N Engl J Med. 2005; 352: 1024.

3) Pappo I, Wasserman I, Stahl-Kent V, Sandbank J, Halevy A. Mondor's disease of the axilla: a rare complication of sentinel node biopsy. Breast J. 2004; 10: 253-5.

4) Mera K, Terasaki K, Kanzaki T, Kanekura T. Mondor's disease on the neck. J Dermatol. 2009; 36: 179180.

5) Mondor H. Tronculite sous-cutanee subaigue de la paroi thoracique antero-laterale. Mem Acad de Chir. 1939; 65: 1271-8.

6) de Godoy JM, Godoy MF, Batigalia F, Braile DM. The association of Mondor's disease with protein $\mathrm{S}$ deficiency: case report and review of literature. J Thromb Thrombolysis. 2002; 13: 187-9.

7) Alvarez-Garrido H, Garrido-Rios AA, Sanz-Munoz C, Miranda-Romero A. Mondor's disease. Clin Exp Dermatol. 2009; 34: 753-6.

8) Cooper RA. Mondor's disease secondary to intravenous drug abuse. Arch Surg. 1990; 125: 807-8.

9) Mayor M, Buron I, de Mora JC, Lazaro TE, Hernandez-Cano N, Rubio FA, et al. Mondor's disease. Int J Dermatol. 2000; 39: 922-5.

10) Ichinose A, Fukunaga $A$, Terashi $H$, Nishigori $C$, Tanemura A, Nakajima T, et al. Objective recognition of vascular lesions in Mondor's disease by immunohistochemistry. J Eur Acad Dermatol Venereol. 2008; 22: 168-73. 